\title{
Deconstruction of Male and Female Characters' Qualities in Zootopia
}

\author{
William Teddy \\ English Department, Faculty of Letters, Petra Christian University,Siwalan Kerto 121-131, Surabaya \\ 60236, East Java, INDONESIA \\ E-mail: m11415003@john.petra.ac.id
}

\begin{abstract}
This research aims to analyze the representation of male and female characters' qualities that are portrayed in Zootopia. The research also aims to show how the qualities are deconstructed as well as how to deconstruct the deconstruction in the movie as a method of analysis. Through the analysis the writer finds that the representation of qualities in Zootopia follows the traditional gender stereotypes, where men are considered superior than women. However, as the story progresses, the writer finds that the qualities in the movie are gradually deconstructed, showing that women are superior than men. After deconstructing the deconstruction in the movie, the writer finds that meaning can "disseminate" or can be perceived in different ways. Furthermore, from the analysis, the writer finds that both oppositions are actually interdependent to each other and complement as a whole. This means neither of the oppositions is stronger or weaker than the other.
\end{abstract}

Keywords: Gender roles, Masculine and Feminine Gender Stereotypes, Deconstruction, Binary Opposition, Violent Hierarchy

\section{INTRODUCTION}

According to Muranda (2016), animation is known as a technique of bringing an object to life (Muranda, 2016). This particular technique requires several pictures that are combined and played together in frames in order to make the pictures look moving and alive. This method nowadays has also become a genre; and has become one of the most popular genres in many years. This genre was especially very popular in 2016. It was proven that three of the ten highest-grossing movies of all time that hit the box office in 2016 were all animated movies, and of them is Zootopia that gulped \$341.3 million (Pressberg, 2016).

Zootopia is one of Disney's animated and featured projects that was written and directed by Byron Howard and Rich Moore. The reasons why the writer decided to choose Zootopia were because of its popularity and the issues that it discussed. Zootopia discusses the issues of women empowerment and the discrimination against women. Interestingly, these issues happen in a fantasy world where only animals live in.

The story is set in a fantasy background where predators and preys live in harmony. Judy, the protagonist of the movie, was a female bunny. Ever since she was a kid, Judy wanted to become a police officer. However, many animal did not respect her decision, even her parents herself. The reason is because there has never been any bunny who become a cop before, and they believe, it is impossible for Judy as a bunny to be a cop. This shows that there are some qualities that are accepted or not accepted within Judy's society. That is why some animal disrespect her decision, because they think Judy is not qualified to be a cop. However, Judy did not give up and she wanted to prove that she could become a cop.

In the end, she managed to join the police department. However, even after becoming a police officer herself, Judy was treated less respected than everyone in the police department (which mostly are males). Similar situation also happens to other females as well. This shows that there are things in males' qualities that make them more respected or considered higher compared to 
the female characters. Interestingly, despite the discrimination towards female characters in the movie, as the story progresses, females are shown more successful or superior than the male characters. This indicates that there are changes in the qualities that are gradually subverted and deconstructed in the movie which change how people perceive the meaning.

The writer is interested to know what qualities of male and female characters being represented in the movie. Furthermore, the writer wants to show how the qualities are gradually subverted or deconstructed in the movie. The writer is also interested to deconstruct the deconstruction in the movie to show how meaning can be perceived in different point of view. To do this, the writer uses two theories which are gender roles and deconstruction as explained below.

"Gender roles" have been described as society's shared beliefs that apply to individuals on the basis of their socially identified sex. Gender roles can also be described as social expectations about appropriate behavior of men and women in a society. Men are generally thought to be competent, independent, masterful, and achievement oriented, while women are perceived as friendly, warm, sociable, interdependent, emotially expressive, and relationship-oriented (Eisenchlas, 2013). In the traditional division of labor, men occupy high status or leadership roles more than women do, and women occupy caretaking and domestic roles than men do. Moreover, gender roles also related to gender stereotypes which tell that male should be masculine and female should be feminine, this results in reinforcing male superiority and female subordination as if it is something natural and acceptable in a society (Eisenchlas, 2013).

There are differences in personality and traits ascribed to men and women. There is considerable agreement across a large number of psychological studies that women are viewed gentle passive, kind, etc, whereas men are viewed tough, aggressive, assertive, etc (Huddy \& Terkildsen, 1993). These labels of traits are labelled to each sex, and the corresponding sex should behave to the expected traits to be considered appropriate in the society. Therefore, men are expected to be masculine and women are expected to be feminine in order to be considered appropriate within the society.

According to planned parenthood organization (2014), there are in total of four gender stereotypes. Traits are included in these gender stereotypes, and these stereotypes are divided as seen below (Planned Parenthood, 2014).

a) Personality traits - For example, women are often expected to be passive, while men are usually expected to be self confident and aggresive.

b) Domestic Behaviors - For example, caring for children is often considered best done by women, while household repairs are often considered best done by men

c) Occupations - For example, until very ecently most nurses and secretaries were usually women, and most doctors and construction workers were usually men.

d) Physical appearance - For example, women are expected to be small and graceful, while men are expected to be tall and broad-shouldered.

According to Taylor (2003) in the book of Teaching Sociology, there are several stereotypes that are given to men and women. For example, men are supposed to be dominant, independent, intelligent, rational, assertive, analytical, strong, brave, and so on. On the other hand, women are supposed to be submissive, dependent, unintelligent, emotional, receptive, intuitive, weak, timid, and so on (Taylor, 2003).

Ottma (2015) explains In the article "What Makes a Man a Real Man" that men are expected to behave in aggressive manner, whereas women tend to be passive. Furthermore, the article mentions that women are more feeling-oriented such as being emotional, sympathetic, soft, nurturing, and caring. On the opposite site, men are more logic-oriented such as logical, 
decision making, rational, and so on. This what makes men different compared to women in how they behave (Ottma, 2015).

According to Verena (2017), on her journal, "How Gender Stereotypes Affect the Image of Entepreneurs Among Young Adult", men are explained as more obedient and better in leading compared to the women. Women on the other hand are explained as helpful, shy, and more understanding in the workplace (Verena, 2017).

Deconstruction is a theory that was first coined in the late 1960's by a French philosopher named Jacques Derrida. In his book Dissemination (1982), Derrida (1982) explains that deconstruction does not refer to the word "destruction, but instead "analysis", which etymologically means "to undo". Deconstruction does not proceed by random doubt generalized skepticism, but the careful teasing out of warring forces of signification within the text itself. This implies that a text signifies in more than one way, and to varying degrees of explicitness (Derrida, Dissemination, 1982). In simple way, deconstruction can refer to a way of reading a text and questioning what is being marginalized or repressed within the text to find explicit meanings within the text.

In his book called Positions(1982), Derrida (1982) explains that in order to deconstruct a text, one needs to locate an opposition in the text. The way to locate an opposition can be done by listing binary oppositions or dichotomies within the text. In this binary opposition or dichotomy, Derrida believes that one word is always more privileged than the other,showing that binaries are unstable or unequal, because one term is always above or superior than the other (Derrida, Positions, 1982). For example, presence over absence, life over death, man over woman, rich over poor, and so on. This idea where people consider one term is supeior over another is what Derrida refers as violent hierarchy. Derrida is against the idea of violent hierarchy; and he believes that without death there will be no life, without women there will be no men, and so on. Derrida wants to say that binary oppositions are supposedly complementingeach other. Thus, deconstruction aims to reveal that both oppositions are actually in equal binary or in simple words both areimportant within the text.

Kakoliris (2004) writes in the journal, “Jacques Derrida's Double Deconstructive Reading: A Contradiction In Terms?"; that deconstruction must first reproduce what the author "wants-tosay". This traditional reading is then destabilised through the utilisation of all those elements that have refused to be incorporated within it. Hence, the meanings become "disseminated" during the second reading (Kakoliris, 2004). It means, it is possible to deconstruct a text twice using deconstruction as a method of analysis. The first reading is what Derrida refers as "Doubling Commentary", and the second reading is what Derrida calls as "Critical Reading" or "Active Intepretation". Through this double reading or what Derrida refers as "Double Gestures", Derrida wants to show that the authors have no power to "control" over the text, instead it is possible for the readers to "disseminate" the text into many "undecideable" meanings.

\section{THE REPRESENTATION OF QUALITIES IN ZOOTOPIA}

Representation is a term that is often used to represent something. In this research, the writer reveals that the representation in Zootopia actually follows a quality or standard. In this case, the writer shows that the representation of qualities in Zootopia actually comes from traditional gender stereotypes where males are portrayed masculine and females are depicted feminine.

\section{Male Characters' Qualities in Zootopia}

The traditional male gender stereotypes for example can be seen through appearance. Males are mostly represented in masculine ways such as tall, big, or broad-shouldered as seen in picture 1 . 


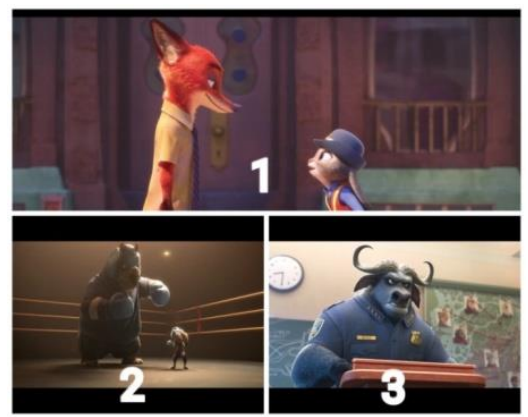

Picture 1 The representation of masculine appearance such as tall, big, or broad-shouldered body for the male characters in Zootopia.

Some other traits such as males being strong and dominant can also be seen portrayed in the movie visually. For example, there is a scene where Judy is having a fight with Gideon, her friend. In this scene, Gideon can be seen much more dominant and stronger when compared to Judy. Judy can also be seen losing against Gideon in this fight which proves that Gideon is more dominant and stronger than Judy is.

Furthermore, in the workplace, males also occupy higher status compared to females. For example chief Bogo is Judy's superior, and Lionheart is the mayor of the city. This shows that leadership can only be done by men.

In conclusion, male characters in Zootopia are represented following the traditional male gender stereotypes such as big, tall, broad-shouldered, dominant, strong, etc . This masculine representation shows that males are superior and much more dominant compared to the female characters in the movie. This then reinforces the idea of male superiority and female subordination as something natural.

\section{Female Characters' Qualities in Zootopia}

The representation of female characters in Zootopia also follows the traditional gender stereotypes. Female characters are mostly depicted in feminine ways. For example in term of appearance, they are mostly represented having small and short body when compared to the male characters. The representation can be seen in the picture 2 .

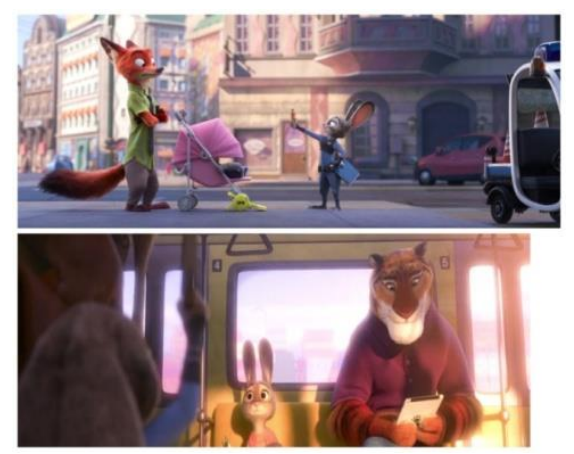

Picture 2 The the representation of feminine appearance for female characters such as small and short body when compared to the males.

For the traits or personalities, female characters in Zootopia can be seen having sympathetic and emotional female gender stereotypes. These two traits can be seen through the actions and 
dialogues of female characters in the movie. For example, Judy can be seen helping her friends to get their tickets back from Gideon which shows that she cares for others. She is also seen emotional, because she can be seen crying and touched in some scenes in the movie.

In term of social status, the female characters are shown as a follower or helper instead of a leader which again proves that they are depicted following traditional gender strereotypes. The examples can be seen from Judy and Bellwhether's case. Judy is chief Bogo's subordinate and Bellwhether is Lionheart's secretary. This shows that they are represented as a follower or helper in the movie.

All the examples above show that females are portrayed in traditional feminine representation. This indirectly reinforces the idea that women are always less significant or weaker compared to men.

\section{DECONSTRUCTION OF QUALITIES' MEANING IN ZOOTOPIA}

Deconstruction refers to the term of analysis which is to undo or dismantle (Derrida, Dissemination, 1982). Deconstruction believes that in this world, everything is divided in binary that contrasts to each other. Nowadays the term is called binary opposition. The examples of binary opposition are like presence and abscence, life and death, man and woman, rich and poor, and so on. In Writing and Difference (1978), Derrida (1978) explains that there is interdependency and totality in a structure (Derrida, Writing and Difference, 1978). This means a structure is divided in two binary oppositions that dependent to each other, and one term is superior than the other. This is what Derrida refers as violent hierarchy. For example, people will prefer life over death, presence over abscence, rich over poor, and so on. This shows that one term is always consideredsuperior or more important when compared to the other.

However, deconstruction wants to reveal that both oppositions are actually important, and they are supposedly in equal binary. Meaning both can be superior or less superior in their own way. In order to do this, Derrida explains that the hierarchy needs to be overturned. This means the marginalized needs to be proven superior than the other to show that both are in equal binary as a whole. Therefore, none is superior, nor weaker than the other.

\section{Deconstruction of Strength}

The representation in Zootopia shows that males are much stronger and superior when compared to the females. This shows that the binary is unstable. Therefore,reinforcing the idea that one is superior than the other. In order to make both oppositions neutral or equal, the hierarchy of the superior one needs to be undermined within the structure to show that the weak is actually can be powerful as well.

Thus, the writer aims to show that despite being represented as the weak, females are actually stronger than the males. For example Judy can be seen winning a fight against a male character as seen in picture below (picture 3).

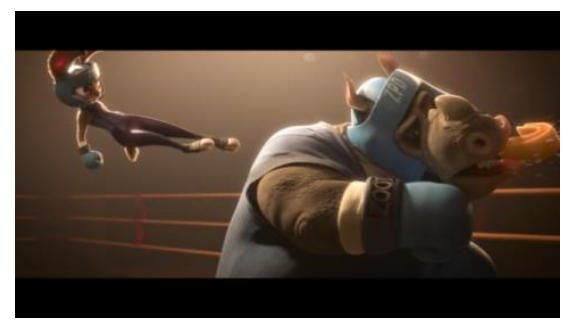

Picture 3 Judy is shown winning against a male character in the movie. 
Despite being represented as the weak, Judy manages to win the fight by using her opponent's power against himself. This shows that she is superior and stronger than her opponent who is a male. This also shows that the meaning of strength has been deconstructed in the movie. Strength is not about muscle anymore, and intelligence can be a strength like how Judy outsmart her opponent. This shows that the deconstruction in the movie has changed how people perceive meaning in the movie.

Another good example that female characters are actually shown more powerful than the male characters can be seen in Bellwhether's situation. Just like Judy, Bellwhether is represented weaker than the males in Zootopia. However, despite being shown weak and small like other female characters in the movie, she is actually more powerful than she looks like.

Bellwhether is very smart. She is even the master mind that makes some predators in Zootopia go savage. She is even successful in framing Lionheart as the criminal in Zootopia. This shows how smart Bellwhether is. This also shows that Bellwhether is actually powerful enough to beat Lionheart as one of the male characters in the movie.

\section{Deconstruction of Leadership}

In Zootopia, the leaderships are dominated by the male characters. For example, Judy's superior and the mayor of the city are all males. This shows only male characters that can become a leader, whereas female characters can only become a follower in term of position. However, the deconstruction in the movie shows that females can also become a leader.

For example, at the very beginning in the movie, many people believe that Judy will never be a cop. However, Judy shows that she can be a cop. This is because she has a will of a leader. If Judy follows what other people say to her, and give up in pursuing her dream, then it is a proof that she is a follower. However, Judy proves herself that she has a control in her life and she is a leader for her own that leads herself to success.

Another proof can be seen from Bellwhether's situation where she shows that she can control men as her subordinates. This shows that leadership can be done by females. It also shows that it is possible for males to become a follower or subordinate of a female as well (picture 4).

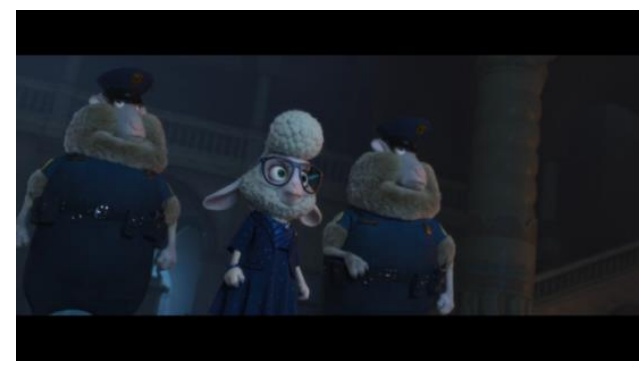

Picture 4 Bellwhether leads some male characters as her subordinates.

\section{DECONSTRUCTING THE DECONSTRUCTION IN ZOOTOPIA}

The writer has shown that the the qualities in the movie are gradually subverted. At first females are shown less superior than males through the representation, which means males occupy a higher position in the violent hierarchy. However, as the story progresses, the movie shows that actually female characters can be more superior compared to the male characters. However, knowing that the hierarchy is now in favor towards females, the writer is interested to do a 
critical reading by applying another deconstructive criticism to the first reading. This is to show that again meaning can be perceived differently from many point of views.

\section{Deconstructing the Deconstruction of Strength}

In the analysis deconstruction of strength, female characters can be seen stronger and superior than the male characters. This again shows that the binary is unstable and need to be stabilized by showing the less superior as the superior one. To do this, the hierarchy where males are weaker needs to be turned upside down to show males are again superior. This can easily be seen through Nick's action in the movie.

Several times Judy are saved by Nick in the movie. The first was when Judy was about to be fired, and Nick argued that Judy still had time to solve the case. The second was when Judy cried in front of Nick and she wanted Nick to help her which later Nick agreed. This shows that Nick saves Judy multiple times from her dire situations which proves that Nick is superior than Judy is. Judy even admits that she cannot do it without Nick's help.

Similar case is also seen in Bellwhether's situation. Just like Judy, Bellwhether needs the help of male characters in the movie which are her subordinates to accomplish her goal. Without the help of her subordinates, Bellwhether may not be successful in doing her plan. This shows that males are stronger than the females, because females need the help of males to be successful.

\section{Deconstructing the Deconstruction of Leadership}

The same also goes to the leadership. Nick can be seen leading Judy throughout her investigation. For example, without Nick, Judy would never meet Yax in Mystic Oasis to find her first clue in finding Mr. Otterton. Nick was also the one who led Judy to DMV (Department of Mammal Vehicles) to track where Mr. Otterton's car went. He was also the one who led Judy to notice the cameras in all over the canopy to continue her investigation. This shows that Nick is always there to show and lead Judy where she needs to go, and Judy is only the follower who follow Nick's directions.

Lionheart also shows that he is a good leader. Even though he abducts the savage predators, he actually only wants to protect the city. He cares for the city, and he tries to protect it at all cost, whereas Bellwhether only cares about herself. Her act brings chaos to Zootopia, and it shows that she only cares about fulfilling her ambition. This shows that Lionheart is better than Bellwhether in leadership, because he cares about the city. This also shows that meaning can be perceived differently by showing another point of view. Thus, there is no a single fixed meaning to intepret a movie. This also shows that the film maker does not fully deconstruct the movie. Because the streotypes are still maintained in the movie (for example: leadership can only be done or better done by men)

\section{CONCLUSION}

In conclusion the representation of qualities in Zootopia is shown following the traditional gender streotypes (men are masculine and women are feminine) where men are perceived stronger or superior than women. However, despite being represented as the weak, the females are shown much superior than the male characters. This shows that the movie is deconstructed by the film maker. After doing the last part of the analysis, the writer finds that it is possible to perceive meaning by changing the point of view from the previous reading. This shows that there many ways to intepret a film. The writer also finds that the film maker does not fully deconstruct the movie, because the traditional gender stereotypes are maintained in the film. 
Furthermore, through the analysis, the writer wants to add that both oppositions are actually interdependent to each other, which means it is not possible to say that one is powerful without the existence of the powerless, nor to say one is powerless without the existence of the powerful. The writer finds that both oppositions are actually important in the movie. Both play an important role, and complement each other in the movie. Therefore, actually none is superior or weaker than the other, both are equal in term of the hierarchy position as a whole.

\section{REFERENCES}

Derrida, J. (1978). Writing and Difference. The University of Chicago Press.

Derrida, J. (1982). Dissemination. The University of Chicago Press.

Derrida, J. (1982). Positions. University of Chicago Press.

Eisenchlas, S. A. (2013). Gender Roles and Expectations: Any Changes Online? Sage , 2.

Howard, B., \& Moore, R. (Directors), \& Spencer, C. (2016). Zootopia [Walt Disney Pictures]. United States: Walt Disney Animation Studios.

Huddy, L., \& Terkildsen, N. (1993). Gender Stereotypes and the Perception of Male and Female Candidates. American Journal , 119-147.

Kakoliris,G.(2004).Jacques Derrida's Double Deconstructive Reading: A Contradiction in Terms? British Society for Phenomenology, 283-292.

Mazarin, J. (n.d.). Gender Roles in Society: Definition \& Overview. Retrieved from https://study.com/academy/lesson/gender-roles-in-society-definition-lesson-quiz.html

Muranda, L. (2016, November 11). So, what exactly is animation? Retrieved from https://www.linkedin.com/pulse/so-what-exactly-animation-lily-muranda

Ottma, J. (2015, August 31). What makes a man a "real man"? Retrieved from https://www.exposingtruth.com/what-makes-a-man-a-real-man/

Planned Parenthood. (2014). Retrieved from https://www.plannedparenthood.org/learn/sexualorientation-gender/gender-gender-identity/what-are-gender-roles-and-stereotypes

Pressberg, M. (2016, August 16). Why Animated Movies Are Dominating the Box Office in 2016. Retrieved from https://www.thewrap.com/why-animated-movies-aredominating-the-box-office-in-2016/

Taylor, F. (2003). Content Analysis and Gender Stereotypes in Children's Books. Teaching Sociology, 300-311.

Verena, S. T. (2017). Revisited: how gender role stereotypes affect the image of entrepreurs among young adult. International Journal of Gender and Entrepreneurship , 319-337. 